\title{
QUALIDADE FISIOLÓGICA DE SEMENTES DE SOJA COM DIFERENTES TEORES INICIAIS DE UMIDADE
}

\begin{abstract}
Márcio Gonçalves da Silva ${ }^{1 *}$, Tainan Lopes de Almeida ${ }^{1}$, Lucas Celestino
Scheunemann ${ }^{1}$, Raimunda Nonata Oliveira da Silva ${ }^{1}$, Luis Eduardo Panozzo ${ }^{1}$

${ }^{*}$ Autor correspondente - marcio.silva027@gmail.com

${ }^{1}$ PPG em Ciência e Tecnologia de Sementes, Universidade Federal de Pelotas, Pelotas, Rio Grande do Sul - Brasil

Recebido em: 08/04/2016 - Aprovado em: 30/05/2016 - Publicado em: 20/06/2016

DOI: 10.18677/Enciclopedia_Biosfera_2016_095

RESUMO

Um dos problemas que muitos agricultores têm encontrado na implantação de lavouras é o excesso de chuvas e consequentemente a elevação da umidade do solo. Este fato, pode acarretar problemas devido ao rápido processo de embebição e danificação do sistema de membranas. Neste sentido, torna-se importante o conhecimento de cada cultivar e a sua susceptibilidade ao dano causado por uma rápida embebição. Assim, objetivou-se avaliar a qualidade fisiológica de sementes de soja, com diferentes teores iniciais de umidade. O ensaio foi arranjado em delineamento inteiramente casualizado, com quatro repetições. Os tratamentos foram constituídos de diferentes teores iniciais de umidade da cultivar NS 5909, totalizando cinco tratamentos, cujas umidades foram, $\mathrm{T} 1=7.6, \mathrm{~T} 2=8.7, \mathrm{~T} 3=10.3$, $\mathrm{T} 4=11.4$ e T5=11.8 \%. Para caracterização da qualidade fisiológica foram realizados os testes de primeira contagem da germinação, germinação, condutividade elétrica, comprimento da parte aérea, comprimento da raiz, comprimento total, massa seca da parte aérea, massa seca da raiz e massa seca total de plântulas. A redução da umidade de 11.8 para $7.6 \%$ reduz a germinação de 94 para $88 \%$ respectivamente, comprometendo o vigor das sementes, como demonstrado nos testes de vigor realizados.
\end{abstract}

PALAVRAS-CHAVE: Desempenho fisiológico; embebição; Glycine max L..

\section{PHYSIOLOGICAL QUALITY OF SOYBEAN SEEDS WITH DIFFERENT INITIAL MOISTURE CONTENT}

\begin{abstract}
One of the problems that many farmers have encountered in the implementation of crops is the excessive rainfall and consequently the increase in soil moisture. This fact can cause problems due to the rapid process of soaking and damaging the membrane system. In this regard, it is important to be aware of each cultivar and its susceptibility to damage caused by a rapid imbibition. The objective was to evaluate the physiological quality of soybean seeds with different initial moisture content. The trial was arranged in a completely randomized design with four replications. The treatments consisted of different initial levels of moisture of the cultivar NS 5909, a total of five treatments, whose humidities were $\mathrm{T} 1=7.6, \mathrm{~T} 2=8.7, \mathrm{~T} 3=10.3,11.4$
\end{abstract}


and $\mathrm{T} 4=\mathrm{T} 5=11.8 \%$. To characterize the physiological quality were performed the first count of germination, germination, electrical conductivity, shoot length, root length, total length, shoot dry weight, root dry mass and total dry mass of seedlings. The reduction of moisture 11.8 to $7.6 \%$ reduces the germination of 94 to $88 \%$, respectively, affecting seed vigor, as demonstrated in the vigor tests.

KEYWORDS: Glycine max (L.); hydration; physiological performance.

\section{INTRODUÇÃO}

A soja (Glycine max L.), atualmente é uma das culturas de maior importância no Brasil e no mundo, por desempenhar funções estratégicas, que são consideradas o pilar do agronegócio brasileiro. As novas estimativas para a próxima safra agrícola são ótimas, indicando uma safra recorde, com produção de 101.18 milhões de toneladas em uma área de 33.24 milhões de ha (CONAB, 2016).

Contribuindo com 48,12\% na produção total de grãos no Brasil, a soja tornase a commodity alvo de grande parte das tecnologias desenvolvidas para o campo. Diversos são os fatores que contribuem para a alta produção, como o desenvolvimento de cultivares adaptadas para diferentes regiões, tecnologia de aplicação, manejo do solo e toda a parte voltada no uso de softwares adotando práticas de agricultura de precisão. Para que todas as tecnologias sejam empregadas de forma eficiente, é importante o uso de sementes de alta qualidade fisiológica, que germinem rapidamente e uniformemente, pois esses fatores, entre outros, podem prejudicar o desempenho de plantas (MARCOS FILHO, 2005; CARVALHO \& NOVEMBRE, 2012; MATTIONI et al., 2012; LAMEGO et al., 2013; TAVARES et al., 2013; ALVES et al., 2015; GAZOLLA-NETO et al., 2015; CANTARELLI et al., 2015a; 2015b).

No Rio Grande do Sul (RS) a semeadura foi prejudicada pelo excesso de umidade do solo, e em muitas áreas, houve a necessidade de ressemeadura devido a chuvas pesadas sobre as lavouras recém semeadas (CONAB, 2015). Esse problema está relacionado com a umidade do solo e também com a umidade inicial das sementes, pois após atingir a maturidade fisiológica, a semente se desprende da planta mãe, e tende a ficar em equilíbrio com o ambiente, o que pode muitas vezes atingir níveis baixos de umidade, e esse também ser mantido e/ou intensificado durante o armazenamento e comercialização. Esse é um fator de maior significância para reduzir o processo de deterioração, pois se mantendo baixo a umidade das sementes, o ataque de micro-organismo e a respiração celular terão seus efeitos minimizados (PESKE et al., 2012).

No processo de germinação é necessária a reabsorção de água, o que leva a uma reorganização considerável do sistema celular, elevando a sensibilidade da semente, podendo ocorrer à liberação de solutos e macromoléculas de maneira profusa ou reiniciar o metabolismo de maneira defeituosa. Estresses durante a embebição, devido à grande diferença de potenciais hídricos entre a semente e o meio fornecedor de água, interferem no restabelecimento das organelas celulares, principalmente das membranas (MARCOS FILHO, 2005; TAIZ \& ZEIGER, 2013).

As membranas possuem dois estados, um mais fluído chamado cristalino líquido e outro menos fluído ou gel. Quando organizadas, as membranas permanecem na forma cristalina, portanto mais secas, quando reidratadas de forma rápida, não há tempo necessário para ser revertida para forma líquida cristalina, ocorrendo danos as células e possíveis injúrias (PESKE et al., 2012).

O tegumento das sementes exerce a função de proteção contra os fatores externos que possam reduzir a qualidade, é muito importante para permitir a ENCICLOPÉDIA BIOSFERA, Centro Científico Conhecer - Goiânia, v.13 n.23; p.1696 2016 
absorção de água, e assim, iniciar o processo de germinação. As características do tegumento influenciam a velocidade de absorção, podendo ocorrer diferenças entre cultivares e danos ocasionados as sementes durante a embebição (COSTA et al., 2002).

Devido a essas características do tegumento, que podem sofrer influência do genótipo e ambiente de produção, torna-se importante o conhecimento de cada cultivar, frente ao dano ocasionado por embebição. Este trabalho teve o objetivo de caracterizar a qualidade fisiológica de sementes de soja, com diferentes teores de umidade inicial, e os danos causados pelo processo de rápida embebição.

\section{MATERIAL E MÉTODOS}

O experimento foi conduzido no Laboratório Didático de Análise de Sementes da Universidade Federal de Pelotas, localizada no estado do RS, cujas coordenadas geográficas são $3152 ' 00$ " de latitude sul e $5221^{\prime}$ ' 24" de longitude oeste e altitude de 30 metros. Foram utilizadas sementes de soja (Glycine max L.) cultivar NS 5909, a qual foi caracterizada inicialmente com germinação de $94 \%$ e umidade de $11.8 \%$ de base úmida.

Para obtenção dos diferentes teores de umidades, colocou-se pequenas porções de sementes em estufa de circulação de ar forçado a $33 C^{\circ}$. Pequenas amostras foram coletadas a cada duas horas para aferição da umidade, determinando assim o período necessário para as sementes atingirem a umidade desejada, nas referidas condições. Posteriormente, em recipiente telado com dimensões de $30 \times 30 \mathrm{~cm}$ em estufa de circulação de ar forçado, a temperatura de $33^{\circ} \mathrm{C}$, colocou-se novas sementes, aproximadamente um $\mathrm{Kg}$, e quatro amostras representativas foram coletadas para realização das avaliações nos períodos prédeterminados. As avaliações realizadas foram: umidade, germinação, primeira contagem de germinação, condutividade elétrica, comprimento de raiz, parte aérea, e total de plântulas e massa seca de raiz, parte aérea e total de plântulas.

A umidade foi determinada pelo método de estufa 105을 durante $24 \mathrm{~h}$, com duas sub amostras. A germinação foi realizada com quatro sub amostras de 50 sementes para cada repetição, colocadas em substrato de papel de germinação "germitest", previamente umedecido em água destilada utilizando-se 2,5 vezes a massa do papel seco em peso de água, e mantido à temperatura de $25^{\circ} \mathrm{C}$. As avaliações foram efetuadas conforme as Regras para Análise de Sementes (BRASIL, 2009) e os resultados expressos em porcentagem de plântulas normais.

A primeira contagem da germinação constou da determinação da percentagem de plântulas normais aos cinco dias após a semeadura por ocasião da realização do teste de germinação. $O$ teste de condutividade elétrica foi realizado nas sementes de soja, segundo metodologia descrita por VIEIRA \& KRZYZANOWSKI (1999) sendo contadas e pesadas quatro subamostras de 50 sementes, de cada tratamento. As amostras foram colocadas em copos de plástico com $75 \mathrm{~mL}$ de água deionizada e mantidas em uma câmara com temperatura controlada a $25{ }^{\circ} \mathrm{C}$, durante $24 \mathrm{~h}$; depois deste período a leitura da condutividade elétrica foi realizada por meio de um condutivímetro.

O comprimento de raiz e parte aérea foi realizado com base em quatro subamostras de 20 sementes para cada repetição, sendo distribuídas em rolos de papel germitest umedecidos com água destilada utilizando-se 2,5 vezes a massa do papel seco, e mantidos em germinador a $25^{\circ} \mathrm{C}$, por c inco dias. Sobre o papel toalha umedecido foi traçado uma linha no terço superior, na direção longitudinal, onde as sementes foram colocadas direcionando-se a micrópila para baixo. O comprimento ENCICLOPÉDIA BIOSFERA, Centro Científico Conhecer - Goiânia, v.13 n.23; p.1697 2016 
da raiz primária e das plântulas consideradas normais foi determinado ao final do quinto dia, com o auxílio de régua milimetrada, e os resultados expressos em cm/plântula.

A massa seca foi realizada com as plântulas obtidas da análise de comprimento, colocando a porção da parte aérea e raiz separadamente em sacos de papel, posteriormente levadas para estufa de circulação de ar forçada a $70{ }^{\circ} \mathrm{C} / 72 \mathrm{~h}$. Após, foi realizada a pesagem das amostras e os resultados expresso em g/plântulas.

O delineamento utilizado foi inteiramente ao acaso (DIC), constituído de cinco tratamentos e quatro repetições. Os tratamentos foram constituídos dos diferentes graus de umidade $T 1=7,6 ; \mathrm{T} 2=8,7 ; \mathrm{T} 3=10,3 ; \mathrm{T} 4=11,4 ;$ e $\mathrm{T} 5=11,8$. A análise estatística consistiu em regressão na análise de variância.

\section{RESULTADOS E DISCUSSÃO}

Sementes de soja da cultivar NS 5909 RG em baixos teores de umidade, têm a qualidade fisiológica reduzida. Conforme observado para os dados de germinação (Figura 1), a umidade inicial das sementes tem forte influência no desempenho germinativo. Quando as sementes foram submetidas ao teste de germinação com diferentes teores iniciais de umidade, houve incremento no potencial de germinação conforme o aumento da umidade inicial dos lotes de sementes. Esse incremento de germinação ocorreu de forma quadrática conforme a elevação da umidade inicial das sementes, este resultado se deve principalmente devido as sementes com umidade inicial acima de $11 \%$ não apresentam danos significativos de embebição. Sementes de amendoim com umidade inicial acima de 10\%, já não apresentam danos no sistema de membranas celulares durante o processo de embebição (BARBOSA et al., 2012). Embora ocorra essa redução no potencial de germinação de sementes, essa qualidade encontra-se dentro dos padrões para comercialização, que atualmente é de $80 \%$ de germinação.

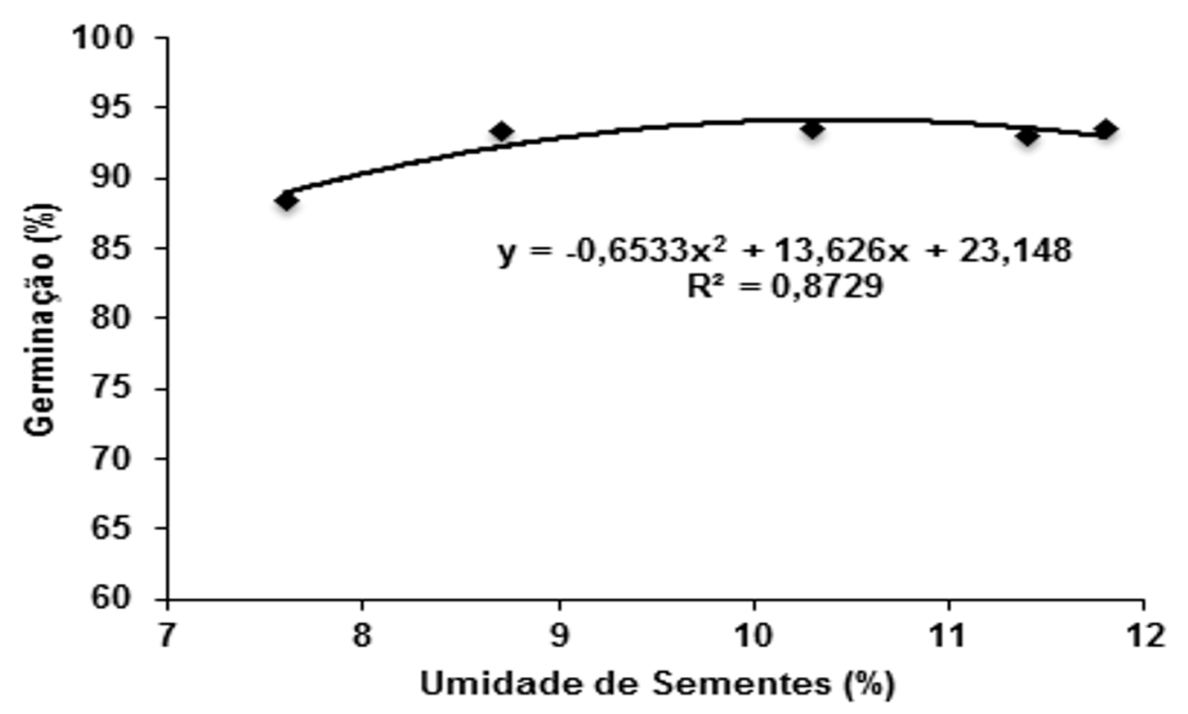

FIGURA 1. Germinação para sementes de soja da cultivar NS 5909, provenientes de sementes com diferentes umidades. Pelotas- RS, 2016. 
De forma similar a germinação, os dados referentes a primeira contagem de germinação foram influenciados pela umidade inicial do lote de sementes. Entretanto, para a primeira contagem de germinação que é um teste de vigor, houve resposta linear positiva conforme o aumento dos teores de umidade inicial das sementes dentro do intervalo de umidade estudado. Este resultado é bastante interessante tendo em vista que em teores de umidade iniciais de sementes acima de $11 \%$ não teve grandes alterações no processo germinativo, mas já para o vigor de sementes avaliado pela primeira contagem da germinação, observou-se aumento linear de resposta em todo intervalo de umidade de sementes avaliado.

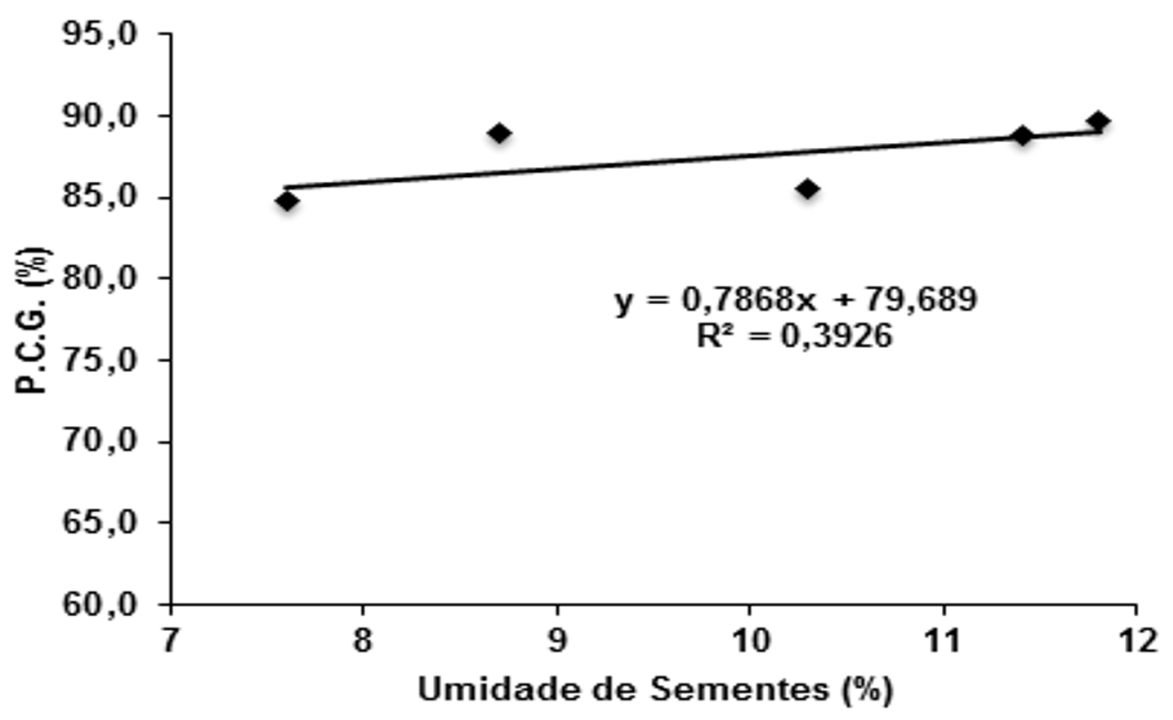

FIGURA 2. Primeira contagem da germinação para sementes de soja da cultivar NS 5909, provenientes de sementes com diferentes umidades. Pelotas- RS, 2016

Durante o processo de hidratação, as sementes podem sofrer danos por embebição, tendo em vista a velocidade com que a água penetra no interior destas, se ocorrer de forma rápida essa pode ocasionar ruptura da estrutura celular e liberação de grande quantidade de solutos (MARCOS FILHO, 2005), causando anormalidade nas plântulas emergidas.

A quantidade de exsudatos liberados pelas sementes durante a embebição, segundo BRAGA et al., (1999), tem sido avaliada pela condutividade elétrica da solução e está relacionado à germinação. Resultados similares também constatados por SILVA \& VILLELA (2011), apresentou redução drástica na qualidade de sementes, quando essas tiveram os teores de umidade reduzidos para $7.5 \%$.

A condutividade elétrica de sementes apresentou redução linear conforme o aumento do teor de umidade inicial das sementes. Este resultado evidencia e explica os resultados de primeira contagem de germinação e germinação de sementes anteriormente apresentados. Conforme o aumento da umidade ocorre redução nos danos de embebição, pois mantêm o sistema de membranas inalterado e consequentemente ocorre menor liberação de solutos, conforme mostra a resposta do teste de condutividade elétrica. Devido a essa menor danificação do sistema membranário foi observada melhora no vigor e germinação de sementes. 
A condutividade elétrica é um teste de vigor utilizado para avaliar a integridade do sistema de membranas. A interpretação é inversamente proporcional ao valor, quanto maior o valor observado, menor é a integridade do sistema membranário, e consequentemente o vigor. Ao realizar a interpretação dos dados, deve-se ter extrema atenção, no tempo em que essa leitura é realizada, pois um lote de alta qualidade fisiológica pode ter uma rápida liberação de solutos e posteriormente se manter inalterado, e um lote de baixa qualidade, ocorrer a liberação e se manter por um período longo.

Um comportamento semelhante foi observado entre os resultados da condutividade elétrica de sementes de soja e amendoim (VIEIRA et al., 2002; BARBOSA et al., 2012), quando verificou-se que houve estabilização em sementes com umidade acima de $11 \%$. O aumento no valor da condutividade elétrica, em função da diminuição do teor de água das sementes está relacionado com o processo de reorganização das membranas celulares, em função da reidratação da semente. Quanto menor o teor de água da semente, maior o estado de desorganização da membrana celular, logo, maior o tempo necessário para que ocorra a reorganização desta e, consequentemente, maior a lixiviação, quando comparada a semente com maior teor de água (BEWLEY \& BLACK, 1985).

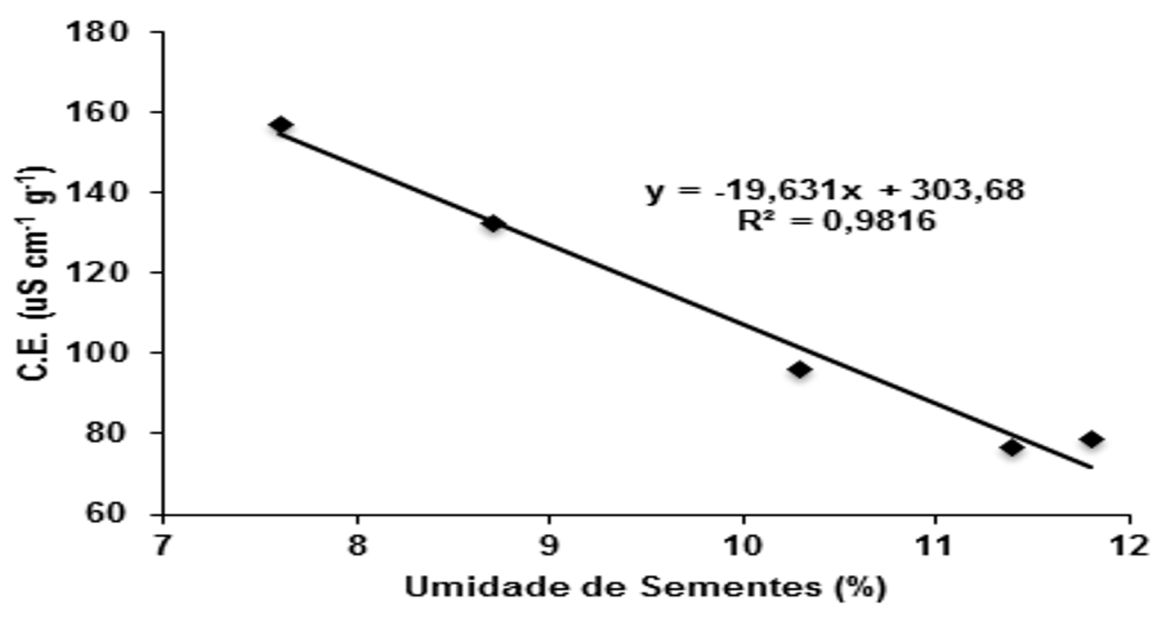

FIGURA 3. Condutividade elétrica (CE) para sementes de soja da cultivar NS 5909, provenientes de sementes com diferentes umidades. Pelotas- RS, 2016.

O comprimento de plântulas e de parte destas também é influenciado pelo teor de umidade inicial das sementes. A resposta do crescimento de parte aérea de plântulas de soja (Figura 4) a elevação do teor de umidade inicial das sementes é cúbica. Resposta semelhante a essa foi observado para o comprimento total de plântulas (Figura 5), entretanto para o comprimento radicular de plântulas não ocorreu alterações de crescimento devido a umidade inicial das sementes.

Os resultados obtidos para o teste de vigor, mediante ao comprimento de plântula, foi possível classificar os lotes em diferentes níveis de qualidade fisiológica das sementes. Com os dados obtidos nesse teste, tem-se uma análise de translocação das reservas contidas nas sementes e como ela é distribuída para as partes constituintes da uma plântula, ou seja, parte aérea e raiz. 


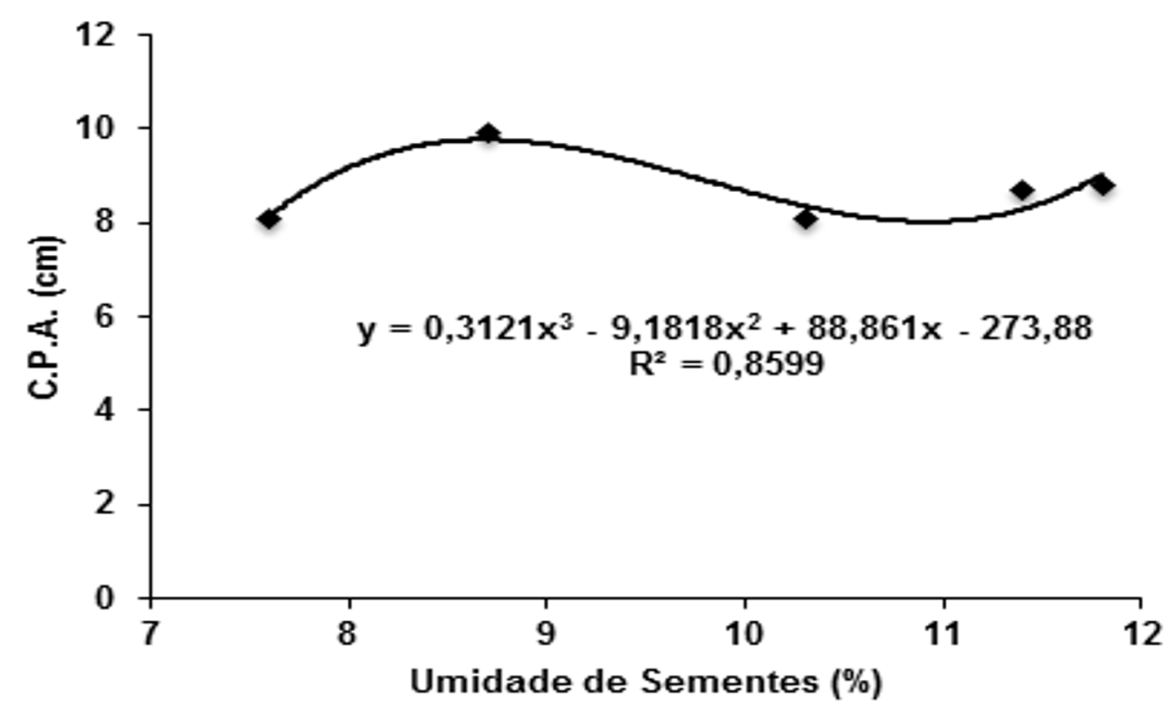

FIGURA 4. Comprimento da parte aérea (CPA) de plântulas de soja da cultivar NS 5909, provenientes de sementes com diferentes umidades. Pelotas-RS, 2016.

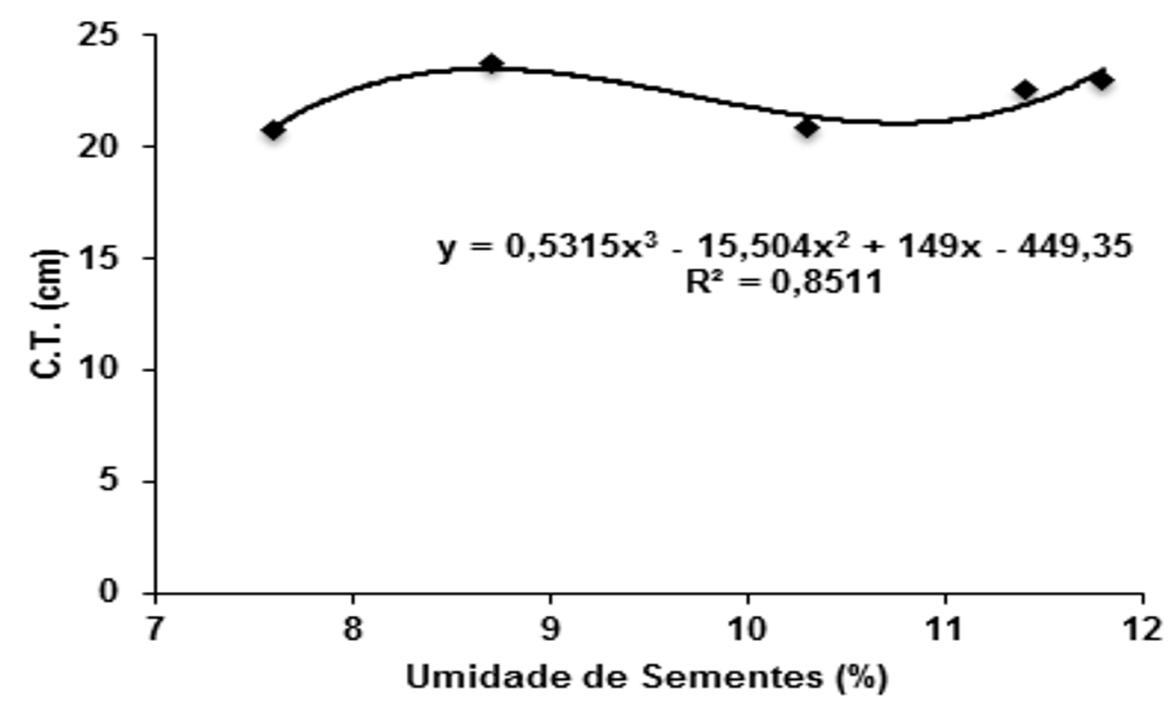

FIGURA 5. Comprimento total (CT) de plântulas de soja da cultivar NS 5909, provenientes de sementes com diferentes umidades. Pelotas-RS, 2016.

Para o desempenho de massa seca de plântulas e de partes destas da cultivar NS 5909, não foi observada diferença significativa para os tratamentos em estudo. A produção de massa seca de plântulas é considerada um teste de vigor, semelhante ao comprimento, informa o quanto das reservas foi translocado para diferentes partes da plântula, mas que em algumas situações não é eficiente para classificar lotes. Esse fato já foi encontrado em estudo realizado com três lotes de sementes de soja da cultivar Embrapa 46, que embora não seja descrita a procedência dos lotes, não foi encontrada diferença significativa (VANZOLINI et al., 2007). 


\section{CONCLUSÃO}

Danos por embebição ocorrem em sementes de soja da cultivar NS 5909, o qual é mais acentuado quando o teor de umidade das sementes for menor que $10 \%$.

\section{REFERENCIAS}

ALVES, C. Z.; ZAQUEU, G. M.; SERAGUZI, E. F.; LEAL, A. J. F.; SILVA, J. B. Production and physiological quality of soybean seeds in orthic quartzarenic neosoil of the cerrado region. Revista Caatinga, v. 28, n. 4, p. 127-134, 2015. Disponível em: http://periodicos.ufersa.edu.br/revistas/index.php/sistema/article/view/4664/pdf_313.

BARBOSA, R. M.; SILVA, C. B.; MEDEIROS, M. A.; CENTURION, M. A. P. C.; VIEIRA, R. D. Condutividade elétrica em função do teor de água inicial de sementes de amendoim. Ciência Rural, Santa Maria, v.42, n.1, p.45-51, jan, 2012. Disponível em:

http://repositorio.unesp.br/bitstream/handle/11449/3312/S010384782012000100008. pdf? sequence $=1$ \&isAllowed $=y$

BEWLEY, J.D.; BLACK, M. Seeds: physiology of development and germination. New York: Plenum, 1985. 367p.

BRAGA, L.F.; SOUSA, M.P.; BRAGA, J.F.; SÁ, M.E. Efeito da disponibilidade hídrica do substrato na qualidade fisiológica de sementes de feijão. Revista Brasileira de Sementes, v.21, n.2, p.95-102, 1999. Disponível em:

http://www.abrates.org.br/revista/artigos/1999/v21n2/artigo16.pdf

BRASIL. Ministério da Agricultura, Pecuária e Abastecimento. Regras para análise de sementes. Brasília: Mapa/ACS, 395 pp. 2009.

CANTARELLI, L. D.; SCHUCH, L. O. B.; RUFINO, C. A.; TAVARES, L. C.; VIEIRA, J. F. Physiological seeds quality: spatial distribution and variability among soybean plant population. Bioscience Journal, v. 31, n. 2, p. 344-351, 2015a. Disponível em: http://www.seer.ufu.br/index.php/biosciencejournal/article/view/22274/16108

CANTARELLI, L. D.; SCHUCH, L. O. B.; TAVARES, L. C.; RUFINO, C. A. Variabilidade de plantas de soja originadas de sementes de diferentes níveis de qualidade fisiológica. Acta Agronómica, v. 64, n.3, p. 234-238, 2015b. Disponível em:

http://search.proquest.com/openview/2be8cddaba4f8fd2d6db955ec8f4fdff/1 ?pqorigsite=gscholar DOI: http://dx.doi.org/10.15446/acag.v64n3.45511

CARVALHO, T. C.; NOVEMBRE, A. D. L. C. Qualidade de sementes de soja colhidas de forma manual e mecânica com diferentes teores de água. Semina: Ciências Agrárias, Londrina, v. 33, n. 1, p. 155-166, jan./mar. 2012. Disponível em: http://www.uel.br/revistas/uel/index.php/semagrarias/article/view/5947/10141

DOI: $10.5433 / 1679-0359.2012 v 33 n 1 p 155$

COMPANHIA NACIONAL DE ABASTECIMENTO. Acompanhamento da safra brasileira de grãos, v. 1, n.1 (2013). Brasília: Conab, 2015. 
COMPANHIA NACIONAL DE ABASTECIMENTO. Acompanhamento de safra brasileira: Grãos, $6^{\circ}$ Levantamento. Março/2016. Brasília: CONAB, 140 pp. Disponível em:

http://www.conab.gov.br/OlalaCMS/uploads/arquivos/16_03_11_15_20_36_boletim_ graos_marco_2016.pdf

COSTA, J. A.; PIRES, J. L. F.; THOMAS, A. L.; ALBERTON, M. Variedades de soja diferem na velocidade e capacidade de absorver água. Scientia Agraria, v.3, n.1-2, p.91-96, 2002. http://ojs.c3sl.ufpr.br/ojs/index.php/agraria/article/view/1036/858

DOI: http://dx.doi.org/10.5380/rsa.v3i1.1036

GAZOLLA-NETO, A.; FERNANDES, M. C.; GOMES, A. D.; GADOTTI, G. I.; VILLELA, F. A. Distribuição espacial da qualidade fisiológica de sementes de soja em campo de produção. Revista Caatinga, v. 28, n. 3, p. 119-127, 2015. Disponível em:

http://periodicos.ufersa.edu.br/revistas/index.php/sistema/article/view/4342/pdf_283

LAMEGO, F.P.; GALLON, M.; BASSO, C.J.; KULCZYNSKI, S.M.; RUCHEL, Q.; KASPARY, T.E.; SANTI, A.L. Dessecaçãopré-colheita e efeitos sobre a produtividade equalidade fisiológica de sementes de soja. Planta Daninha, ViçosaMG, v. 31, n. 4, p. 929-938, 2013. Disponivel em:

http://www.scielo.br/scielo.php?pid=S010083582013000400019\&script=sci_abstract \&tlng=pt DOI: http://dx.doi.org/10.1590/S0100-83582013000400019

MARCOS FILHO, J. Fisiologia de sementes de plantas cultivadas. Piracicaba: Fealq, 2005. 495p.

MATTIONI, F.; ALBUQUERQUE, M. C. F.; MARCOS-FILHO, J.; GUIMARÃES, S. C. Vigor de sementes e desempenho agronômico de plantas de algodão. Revista Brasileira de Sementes, vol. 34, oㅜ 1, p. 108-116, 2012. Disponível em: http://www.scielo.br/pdf/rbs/v34n1/a14v34n1

PESKE, S.T.; VILLELA, F. A.; MENEGHELLO, G. E. Sementes: Fundamentos Científicos e Tecnológicos. $2^{\circ}$ ed. Pelotas, UFPel. 573 p. 2012.

SILVA, K.R.G.; VILLELA, F.A. Pré-hidratação e avaliação do potencial fisiológico de sementes de soja. Revista Brasileira de Sementes, v.33, n.2, p.331-345, 2011. Disponível em: http://www.scielo.br/pdf/rbs/v33n2/16.pdf http://dx.doi.org/10.1590/s0101-31222011000200016

TAIZ L \& ZEIGER E. 2013. Plant Physiology. 5 ed. Sinauer Associates. 782p.

TAVARES, L.C.; RUFINO, C.A.; BRUNES, A.P.; TUNES, L.M.; BARROS, A.C.S.A.; PESKE, S.T. Desempenho de sementes de soja sob deficiência hídrica: rendimento e qualidade fisiológica da geração F1. Ciência Rural. v. 43, n. 8, p. 1357-1363, 2013. Disponível em: http://www.scielo.br/pdf/cr/v43n8/a22213cr2012-0950.pdf DOI: http://dx.doi.org/10.1590/S0103-84782013000800003

VANZOLINI, S.; ARAKI, C. A. S.; SILVA, A. C. T. M.; NAKAGAWA, J. Teste de comprimento de plântula na avaliação da qualidade fisiológica de sementes de soja. ENCICLOPÉDIA BIOSFERA, Centro Científico Conhecer - Goiânia, v.13 n.23; p.1703 2016 
Revista Brasileira de Sementes, Brasília, DF, v. 29, n. 2, p.90-96, 2007. Disponível em: http://www.scielo.br/pdf/rbs/v29n2/v29n2a12.pdf

DOI: http://dx.doi.org/10.1590/S0101-31222007000200012

VIEIRA, R. D.; KRZYZANOWSKI, F. C. Teste de condutividade elétrica. In: Krzyzanowski, F. C.; Vieira, R. D.; França Neto, J. B. (ed.). Vigor de sementes: Conceitos e testes. Londrina: ABRATES, 1999. Cap.4, p.1-26.

VIEIRA, R.D.; PENARIOL, A. L.; PERECIN, D.; PANOBIANCO, M. Condutividade elétrica e o teor de água inicial das sementes de soja. Pesquisa Agropecuária Brasileira, v.37,

n.19,

p.1333-1338, 2002.

http://www.scielo.br/pdf/pab/v37n9/13209.pdfDOI:

http://www.scielo.br/pdf/pab/v37n9/13209.pdf 